the parents of children fed in Willesden were as follows :-

\begin{tabular}{|lllll|c|}
\hline \multicolumn{2}{|c|}{ Status of parents of children fed. } & Percentage. \\
\hline Widows & $\ldots$ & $\ldots$ & $\ldots$ & $\ldots$ & 30 \\
War Widows, Soldiers & $\ldots$ & $\ldots$ & 25 \\
Labourers & $\ldots$ & $\ldots$ & $\ldots$ & $\ldots$ & I9 \\
Fathers in Institutions & $\ldots$ & $\ldots$ & 8 \\
Mothers deserted & $\ldots$ & $\ldots$ & $\ldots$ & 8 \\
Fathers interned & $\ldots$ & $\ldots$ & $\ldots$ & 4 \\
Fathers physically unfit & $\ldots$ & $\ldots$ & 3 \\
Both parents dead & $\ldots$ & $\ldots$ & $\ldots$ & 2 \\
Fathers prisoners of war & $\ldots$ & $\ldots$ & I \\
\hline
\end{tabular}

All the above cases were in absolute poverty.

\section{RESUL'TS OF FEEDING.}

Owing to the shortage of medical and nursing staff in Willesden, it has not been possible during the war to keep records of the effects of feeding on school children, but the general testimony of teachers and all engaged in the work is that the health and nutrition of the children are improved, and the children are brighter and better able to cope with the work of education.
NOTES ON CASES OF CEREBRO-SPINAL FEVER IN THE WEST RIDING ADMINISTRA'TIVE AREA,*

BY

W. A. BUlloUGH, M.B., Сн.B., M.Sc., D.P.H., Acting County Medical Officer, West Riding County Council, Yorkshire.

I DO not intend to discuss this disease from the microscopical and bacteriological standpoint, as that aspect chiefly belongs to the laboratory specialist, but rather from the clinical and preventive standpoint, which is of more practical interest to medical officers of health.

Cerebro-spinal meningitis became compulsorily notifiable for the whole of England and Wales on the Ist September, IgI2. During I9I3 there were notified 279 cases and 3 I 5 cases in IgI4. These were obviously sporadic cases, which were cropping up in all parts of the country from no obvious source. In I9I5 a very different state of affairs quickly supervened. The weekly incidence shot up during February and March, until by the middle of the latter month there were over 200 cases (military and civil) notified in one week. The incidence oscillated slightly at this high

*Paper read before the Yorkshire Branch on Febtuary 9 th, $19 x 7$.

\begin{tabular}{|c|c|c|c|c|c|c|}
\hline & $\begin{array}{l}\text { Scale of Wi1 } \\
\text { the Feeding }\end{array}$ & $\begin{array}{l}\text { esden Education } \\
\text { of School Children } \\
\text { December, I } 6 \text { 6 }\end{array}$ & $\begin{array}{l}\text { Authority for } \\
\text { adopted } 6 \text { th }\end{array}$ & $\begin{array}{l}\text { Equivalent } \\
\text { Ist Mar }\end{array}$ & $\begin{array}{l}\text { Scale at } \\
\text { 1, 1917. }\end{array}$ & $\begin{array}{l}\text { Separation Allow- } \\
\text { ances for London } \\
\text { per week includ- } \\
\text { ing Allotments }\end{array}$ \\
\hline $\begin{array}{l}\text { Number in } \\
\text { Family. } \\
\text { (I) }\end{array}$ & $\begin{array}{l}\text { Total Incomes } \\
\text { per week. } \\
\text { (2) }\end{array}$ & $\begin{array}{l}\text { Average Total } \\
\text { Outgoings per } \\
\text { family per week } \\
\text { in respect of } \\
\text { rent, insurance, } \\
\text { fares to and from } \\
\text { work, and care of } \\
\text { children. } \\
\text { (3) }\end{array}$ & $\begin{array}{l}\text { Net Incomes per } \\
\text { head per week, } \\
\text { of the family. }\end{array}$ & $\begin{array}{l}\text { Net Incomes per } \\
\text { head per week } \\
\text { of the family. } \\
\text { (5) }\end{array}$ & $\begin{array}{l}\text { Total Incomes } \\
\text { per week. } \\
\text { (6) }\end{array}$ & (7) \\
\hline $\begin{array}{r}2 \\
3 \\
4 \\
5 \\
6 \\
7 \\
8 \\
9 \\
10\end{array}$ & $\begin{array}{l}22 / 6 \\
27 /- \\
32 /- \\
36 /- \\
38 / 6 \\
44 /- \\
49 /- \\
55 /- \\
60 /-\end{array}$ & $\begin{array}{l}6 / 6 \\
7 / 6 \\
8 /- \\
8 / 6 \\
8 / 6 \\
9 /- \\
9 /- \\
\text { 10/- } \\
\text { 10/- }\end{array}$ & $\begin{array}{l}8 /- \\
6 / 6 \\
6 /- \\
5 / 6 \\
5 /- \\
5 /- \\
5 /- \\
5 /- \\
5 /-\end{array}$ & $\begin{array}{l}10 /- \\
8 /- \\
7 / 6 \\
6 / 6 \\
6 /- \\
6 /- \\
6 /- \\
6 /- \\
6 /-\end{array}$ & $\begin{array}{l}26 / 6 \\
31 / 6 \\
38 /- \\
41 /- \\
44 / 6 \\
51 /- \\
57 /- \\
64 /- \\
70 /-\end{array}$ & $\begin{array}{l}23 /- \\
28 /- \\
31 / 6 \\
34 / 6 \\
37 / 6 \\
40 / 6 \\
43 / 6 \\
46 / 6 \\
49 / 6\end{array}$ \\
\hline
\end{tabular}


level for a few weeks, and then dropped down to normal in June and July. Altogether in IgI5 there were notified 2,566 cases among the civilian population, and I, I 46 cases amongst soldiers, excluding those originating overseas.

A similar outbreak occurred in 19I6, but a little later in the year, and on a less scale.

There were good reasons for considering that the overcrowding in some military centres, and the return of soldiers either suffering from the disease or having been in contact with actual patients, constituted a serious menace to the civilian population at home. Accordingly, most public health authorities were on the look-out for any suspicious cases of this disease, and made adequate preparations for dealing with any cases so found.

The Local Government Board issued a special circular and memorandum on February 22nd, I 9 I 5 , on this subject, which amplified a previous circular by suggesting definite lines of action to prevent the spread of infection. Accordingly, the following circular was sent out from the County Hall, Wakefield, to each medical practitioner practising in the Riding through the medium of the local medical officer of health :-

\section{WEST RIDING COUNTY COUNCII. Cerebro-Spinat, Meningitis.}

This rapidly fatal disease is showing a tendency to become manifest in the County. I am authorised by Dr. J. R. Kaye, the County Medical Officer, to say that he is prepared to send Dr. Bullough to help you with any suspicious cases and if necessary perform lumbar puncture and take swabs of contacts. The results of the examinations would be communicated at the earliest possible opportunity.

$$
\begin{aligned}
& \text {........... M.O.H. } \\
& \ldots \ldots \ldots \ldots \text { District }
\end{aligned}
$$

March, IgI5.

N.B.-Note that the proffered help is particularly for doubtful or suspected cases.
My own name appeared so prominently in the above circular for two reasons: (I) Dr. P. I. Sutherland, the County Bacteriologist, could not afford the time away from his laboratory, so I accepted the lowly but useful role of collecting specimens for him to examine. (2) It could not be said, as one county medical officer put it, that an " expert" would visit any suspicious cases, for the reason that prior to that time I had only seen two real cases, and, moreover, had never performed lumbar puncture or seen it done. My own experiences ought to encourage those practitioners who have hitherto not attempted this important aid to diagnosis and treatment, as with a little care and experience this useful operation is quite easily performed.

The circular went out in March, IgI5, and just previously to that I had been asked to see two suspected cases, one of which proved to be the specific cerebro-spinal meningitis. For a few weeks following, requests for assistance came in almost daily, but as expected, this fell off towards July, only to be renewed again in December and the early months of rgr6.

During this period I have been to all parts of the Riding, and have seen 59 cases in all, of which II proved to be actual cases of cerebrospinal meningitis. Lumbar puncture was performed on 48 occasions, and a positive diagnosis was only made on finding the diplococcus meningitidis intracellularis of Weichselbaum in the cerebro-spinal fluid. By these means a considerable number of cases, which had been notified as cerebro-spinal meningitis prior to a specimen of the cerebro-spinal fluid being obtained, had their notifications withdrawn on examination of the fluid revealing the true nature of the disease (commonly tubercle). With these corrections the monthly incidence of cases in the Administrative area was as set out below (civilian cases only).

These figures, although on the small side, coincide with the general experience that the disease is most prevalent in spring and early summer.

Contacts.-Whenever an examination of the

\begin{tabular}{|c|c|c|c|c|c|c|c|c|c|c|c|c|c|}
\hline & Jan. & Feb. & Mar. & April. & May. & June. & July. & Aug. & Sept. & Oct. & Nov. & Dec. & Tota! \\
\hline Igr $5 \ldots$ & - & - & 2 & $\mathbf{I}$ & $\mathbf{I}$ & - & - & - & - & - & - & I & 5 \\
\hline Igr6... & 4 & - & - & 5 & - & - & - & - & - & - & I & I & II \\
\hline
\end{tabular}
cerebro-spinal fluid revealed the presence of 
the meningococcus, swabs were taken from the post-pharyngeal spaces of the persons who had been in contact with the patient. The swabs devised by Dr. R. M. Buchanan, of Glasgow, were used, and have proved extremely efficacious and easy to work with. The swabs were either taken straight to the laboratory, so that not more than two hours at the most should elapse between the taking of the swab and implantation on the medium, or, better still, were immediately rubbed on nutrient medium at the house of the patient. This is absolutely necessary; especially in cold weather, as the organisms quickly die on exposure to cold or drought ; for that reason it is almost useless to send swabs through the post. Another precaution which must be taken is to ascertain that no antiseptic nasal douching or gargling of the throat has immediately preceded the taking of the swabs. This is a very common error made by nurses in taking swabs for diphtheria at fever hospitals and elsewhere.

The nutrient medium used was blood serum, to which 'glucose and neutral red were added.

In connection with six of the II cases, positive contacts were found, amounting to ro persons in all who harboured the meningococcus in the posterior pharynx. In each case, after nasal douching and isolation for two to three weeks, the meningococcus could not be discovered on taking further swabs.

A good deal of work has recently been done on the various strains of naso-pharyngeal cocci, which resemble the meningococcus very closely. It has been found that organisms indistinguishable from meningococci are found on the nasopharynx of as many as ro per cent. of persons who have not been in contact with the disease. Serological tests do not help very much, as different strains of undoubted meningococci differ amongst themselves in their serological reactions, and that therefore a negative result with a naso-pharyngeal strain tested upon a particular serum does not justify the exclusion of that strain from the meningococci. We must conclude that the meningococcus has a wide distribution, and it may be that some of its strains found in the naso-pharynx are virulent, whilst others are relatively harmless.

EPIDEMICITY.--With one exception, all the actual cases of the disease were isolated sporadic cases. The exception has some interesting features, and is as follows: A sailor left H.M.S. Mars about the middle of February, 1915, and called at Chatham Naval Barracks for one night before proceeding to his home in Pontefract, where he stayed from February 22nd to 25th. There had recently been cases of cerebro-spinal meningitis at the Chatham Barracks. A few days after his return to his ship, viz., on March Ist, his wife and mother-inlaw were taken suddenly ill with intolerable headache, vomiting, hyperæsthesia, and a purpuric rash over the body and limbs. The mother-in-law quickly lapsed into unconsciousness and died. I saw the wife at the isolation hospital, and after some trouble, owing to the arching of the spine, succeeded in obtaining some fluid, which was found to contain a great number of meningococci. Two days later I took swabs of all the contacts (including the sailor, who had come home in the meantime), and in two cases the result was positive. The meningococcus was not found either in the throat of the patient or the sailor. Allowance must be made for the length of time intervening between February 22nd$25^{\text {th }}$ and March $3 \mathrm{rd}$. This is the only instance where more than one person suffered from this disease who had contracted it from a common source.

Age and Sex of Patient.-Ages of the positive cases were as follows:-

$\begin{array}{llllllll}\text { Females...... } & 25 & 57 & 3 & 24 & 4 & \\ \text { Males } \ldots \ldots & 44 & 33 & 5 & 13 & 3 & 2\end{array}$

This shows a greater relative number of adults than usual, but this may be due to the diagnosis not being so carefully ascertained in the case of infants as with adults.

Signs and Symptoms.

I. Abrupt onset.-In only two cases was the onset described as gradual. The remainder were characterized by the extreme suddenness of the onset, the patient being perfectly well one moment and seriously ill the next.

2. Headache.-This was a marked and early symptom in every case, and generally referred to the occiput. The pain was often of an absolutely intolerable nature, and the only relief was by lumbar puncture, which acted quite magically on numerous occasions.

3. Vomiting.-In nine cases this was marked not only accompanying the onset of the disease, but persisting for some days, and occurring independently of taking food.

4. Hyperasthesia and Restlessness.-This was extremely marked in most cases, and continuing to some degree even when the patient was in a semi-comatose condition. 
The patient often became temporarily delirious, shouting at the top of his voice, and needing considerable attention to keep him under restraint.

5. Kernig's Sign.-This was always present.

6. Rigidity of neck.-'This was always present, although in a varying degree. It increased during the first few days of the disease, and was never missed if the patient's head was carefully rotated in an antero-posterior plane. In three cases the rigidity became so severe as to assume the condition known as opisthotonos.

7. Eruptions.-These are of less importance than any of the above signs or symptoms, but probably led to a suspicion of the true nature of the disease, more often than the more invariable and pathognomonic signs. In five cases there was a purpuric rash, in one case the rash was morbilliform, and in five cases there was no rash observed. A serum rash was noticed in one case only, first noticed nineteen days after the first injection of serum. This was more delayed than usual, and as it was accompanied by a temperature of IOI $^{\circ} \mathrm{F}$. for a few days, it may have been a recrudescence of meningitis, and not merely a serum rash.

Mental State of Patient.-This is often very characteristic. The patient often seems to be in a confused stupor, and on being questioned, will appear by a terrific mental effort to make a reply. He will then quickly relapse into the stuporose resistive state, and make no attempt to continue the conversation.

Mortality.-Of the II cases, 6 died and 5 have recovered. Of the 6 deaths, 4 took place within 5 days of the onset of symptoms, whereas the remaining two dragged on for months before succumbing. Deafness and marked wasting were prominent during the last days of these two lingerers. Of the five survivors, I am informed by their private attendant that all have made complete recoveries:

Differential Diagnosis.-The essential point concerning the circular sent out by the county medical officer was to render the resources of the county laboratory available for aiding diagnosis particularly in reference to doubtful cases. It is not to be wondered at that help was asked for in many cases that proved to be diseases other than cerebro-spinal meningitis. Amongst these other diseases were hysteria, acute osteomyelitis of the femur, tetanus, typhoid, myelitis, pneumonia, influenza, acute anterior poliomyelitis, and meningitis due to other organisms, viz., tubercle and pneumococcus. The more cases I saw and the more was I convinced that a diagnosis cannot be made on mere signs and symptoms. I have taken cerebro-spinal fluid from patients who exhibited in every particular the classical features of the disease, and yet chemical, microscopical, and biological examination of the fluid either showed no evidence of meningitis, or, if so; to be due to the tubercle bacillus or less frequently the pneumococcus. On the other hand, the two cases already referred to in which the onset was gradual, I did not strongly suspect cerebro-spinal meningitis until a turbid fluid was obtained from the spinal canal.

I umbar puncture is, generally speaking, so very easy to perform and almost devoid of any danger provided proper precautions are taken that it cannot be too strongly insisted upon that it should be performed without hesitation whenever the signs and symptoms suggest meningitis.

The chief difficulty is in deciding whether the patient is suffering from meningitis or whether the condition is one known as meningism, due to a toxæmia set up in another part of the body, e.g., acute pneumonia, typhoid fever, etc., but the safe rule seems to be that when you have alternating headache and delirium, rigidity of neck, persistent vomiting, kernig's sign, and hyperæsthesia, lumbar puncture should be performed without delay.

It has amused me more than once to notice how very eminent physicians are apt to be dogmatic in the most doubtful cases without taking every possible step to fortify and clinch their speculative diagnosis. The following are my notes on two cases:-

(I) Boy aged I6. I1l for three weeks with headache and malaise. Private doctor first thought of typhoid, but a specialist said it was cerebro-spinal meningitis, although no cerebro-spinal fluid or swabs were taken. It was a typical case of tubercular meningitis, which was confirmed by lumbar puncture.

(2) Boy aged Io began to be ill ten days ago with pain in right hip and a distinct limp. Later he became delirious with marked hyperæsthesia. Some headache, but on vomiting, and no retraction of head. Specialist ignored hip, and said it was 
acute toxæmia, and probably cerebrospinal meningitis. It was acute osteomyelitis of femur, and on incising nearly a pint of pus came away.

There is no necessity to enter into the technique of this operation, excepting to note the importance of having the patient's back bent forward as much as possible and the knees drawn up. To attain this, chloroform may be necessary, but I only used it on two or three occasions. The needle should be provided with a stylet, and if bone hinders the passage forward into the pia-arachnoid space, a free passage is generally obtained by tilting the point of the needle slightly upward.

The fluid was at an increased pressure in almost every case where meningitis was present, and sufficient fluid was taken away until the pressure became normal, viz., when a drop leaves the needle every two or three seconds.

If the fluid is purulent and turbid, the diagnosis can almost be made at once. But a faint opalescence is not uncommon at a very early or a late stage of the disease. When this is the case, and only a few cocci are likely to be present, it is a good plan to immediately transfer a drop on to a sloped serum tube and incubate, or to incubate the lumbar fluid itself for 12-24 hours. The meningococcus was found on one occasion when the cerebro-spinal fluid was obtained post mortem, three days after death had taken place.

It is interesting to note that during I 916 an increasing number of specimens have been taken by general practitioners themselves, and it would be a great advantage if every medical man would gain the necessary proficiency for this purpose. Dr. Sutherland will be very glad to provide medical men with sterilised tubes and necessary outfit, etc., from the county laboratory. It ought to be said here that with one or two exceptions, all the specimens referred to have been examined by Dr. P. L. Sutherland, the County Pathologist and Bacteriologist.

IsOLATION.- In most cases where the patient was not too ill to be removed, isolation in a fever hospital was obtained. In many places patients have been in wards of general hospitals without any spread of infection. The difficulty was in knowing how to deal with the contacts. At first, each contact was either confined to his home or removed to an isolation hospital. Later, restrictions were only placed on those persons who were found to harbour the meningococcus on their naso-pharynx. The question of compensation for time lost from work then arose, but the Local Government Board refused to authorise compensation for such purposes. Again, there are no general legal powers to compulsorily detain or isolate such persons, as they cannot be described as suffering from any disease, even though they harbour the germ in their upper air passages. Accordingly, in dealing with sporadic cases only I am of the opinion that too much restriction is harmful and unnecessary. Positive contacts should be supervised in the same way as smallpox contacts, told to get out in the fresh air as much as possible, but avoiding public places, such as chapels, schools, cinemas, publichouses, etc. Nasal douching with any mild antiseptic lotion should be carried out, and if another swab is taken in a week or fortnight's time, it is rare to find the specific germ persisting. Vaccines are not much good for clearing the throat.

Serum Treatment.-I had very few opportunities of observing the effect of serum treatment, although I often gave I0-I5 c.c.'s on the date of first seeing the case, whenever the cerebro-spinal fluid was turbid and contained pus.

Prevention.-The best means of prevention are:-early and accurate diagnosis based on examination of the cerebro-spinal fluid, isolation of patient, search for positive contacts with subsequent precautionary methods, avoidance of over-crowding, and removal of conditions which conduce towards catarrhal affection of the nose and throat.

Conclusion.-The main points of these notes are :-

I. To encourage the practice of lumbar puncture in suspicious cases of meningitis.

2. To encourage co-operation of the medical officer of health and medical practitioner in any notifiable infectious disease, with a view to obtaining assistance from existing laboratories.

3. A case should not be notified as cerebrospinal meningitis until after lumbar puncture has enabled the diagnosis to be confirmed.

4. The value of the result after swabbing contacts is still uncertain, but for the present the safe plan seems to-be supervision of those contacts who harbour in their naso-pharynx a coccus which is indistinguishable from the meningococcus. 